\title{
Overgeneral Autobiographical Memory and Depressive Disorder in Children
}

\author{
Nathalie Vrielynck, Sandrine Deplus, and Pierre Philippot \\ University of Louvain
}

\begin{abstract}
Overgeneral autobiographical memory seems to be a stable cognitive marker in depressed adults and may predict persistence of depression. This study investigated whether depressive disorders in children are associated with overgeneral memory. Sixty children (ages 9 to 13 years) participated; 15 were diagnosed with lifetime depressive disorder, 25 had other lifetime psychiatric disorders, and 20 had no history of psychiatric disorder. Depressed children gave fewer specific memories compared to children with no or other psychiatric disorders, even after controlling for depressive mood, potential traumatic life events, verbal IQ, and verbal memory.
\end{abstract}

Autobiographical memory relates to the capacity of people to recollect personal events and facts from their life (Conway \& Pleydell-Pearce, 2000). The recollection of personal events varies in term of specificity. Specific memories refer to unique events that occurred at a particular time and place. In contrast, general memories refer to summaries of repeated occasions (i.e., generic memories) or to events lasting more than $24 \mathrm{hr}$ (i.e., extended memories). When depressed adults are instructed to recall memories of specific autobiographical events following cue words, they are more likely than nondepressed controls to retrieve general memories, irrespective of cue valence (for a review, see van Vreeswijk \& de Wilde, 2004). This process is called overgeneral memory retrieval. For example, when instructed to recall an event during which he or she felt happy, a depressed individual might answer "I'm happy when I'm on holidays" or "I was happy during my 3-week trip to Canada" instead of "I was happy when I visited Niagara Falls for the day." The first response is categorized as a generic memory, the second as an extended memory, and the third as a specific memory.

Overgenerality of autobiographical retrieval was also found in clinical groups other than depressed groups, even after controlling for depressive symp-

The writing of this article has been facilitated by Grants 8.4510.99 and 8.4505.00 from the Fonds National de la Recherche Scientifique de Belgique. The data collection has been made possible by the UCL Psychology Department Consulting Center and the help of Hélène Laroche.

We appreciate the helpful comments of Kate Burns on an earlier draft of this article. We extend special thanks to all the children who participated in the study and to the educational and psychological teams of the Les Tilleuls at Mont-Saint-Guibert, the St. Jean 23 school in Bruxelles, and the Les Horizons Nouveaux school in Tournai, Belgium.

Correspondence should be addressed to Nathalie Vrielynck, University of Louvain, Place Cardinal Mercier, 10, 1348 Louvain-laNeuve, Belgium. E-mail: nathalie.vrielynck@psp.ucl.ac.be toms: posttraumatic (e.g., McNally, Lasko, Macklin, \& Pitman, 1995) and acute stress disorders (Harvey, Bryant, \& Dang, 1998), schizophrenia (e.g., Riutort, Cuervo, Danion, Peretti, \& Salamé, 2003), and eating disorders (e.g., Dalgleish et al., 2003; Laberg \& Andersson, 2004). Nevertheless, overgeneral memory does not seem to be a feature of psychopathology in general. For example, it was not observed in people with anxiety disorders such as social phobia (e.g., Wenzel, Werner, Cochran, \& Holt, 2004) or general anxiety disorder (Burke \& Matthews, 1992).

A wealth of studies has demonstrated the clinical relevance of the overgeneral memory phenomenon. Depressed adults who retrieve more general memories take longer to recover from depression (Brittlebank, Scott, Williams, \& Ferrier, 1993) and are more hopeless (e.g., Evans, Williams, O’Loughlin, \& Howells, 1992). Moreover, they show deficits in interpersonal problem solving (e.g., Evans et al., 1992; Goddard, Dritschel, \& Burton, 1996), are prone to rumination (e.g., Goddard et al., 1996), and have difficulty imagining the future in a specific way (e.g., Williams et al., 1996).

It has been suggested that overgeneral memory is a stable cognitive style that does not disappear when depression has remitted (e.g., Mackinger, Leibetseder, Pachinger, \& Fartacek, 2000; Nandrino, Pezard, Poste, Reveillere, \& Beaune, 2002). Overgeneral memory seems to be a marker of vulnerability to depression, rather than a marker of depression itself (Gibbs \& Rude, 2004). Some studies have reported that overgeneral retrieval is independent of self-reported depressive mood (e.g., Henderson, Hargreaves, Gregory, \& Williams, 2002; Kuyken \& Brewin, 1995; Wessel, Meeren, Peeters, Arntz, \& Merckelbach, 2001). However, others have observed the opposite (e.g., Moffitt, Singer, Nelligan, Carlson, \& Vyse, 1994; Sampson, Kinderman, Watts, \& Sembi, 2003). These incongruent results could be explained by the following ratio- 
nale. Although vulnerability to depression is relatively stable, depressive mood varies. At times, its level can be low, even in individuals vulnerable to depression. This might explain why some studies did not find a relation between depressive mood and overgeneral memory (e.g., Kuyken \& Brewin, 1995; Wessel et al., 2001). However, depressive mood is, on average, higher in individuals vulnerable to depression than in other people. This might account for other studies that reported a significant correlation between depressive mood and overgeneral memory (e.g., Moffitt et al., 1994; Sampson et al., 2003).

Several nonmutually exclusive explanations have been proposed to account for the overgeneral memory bias. One explanation focuses on the impact of traumatic life events. Williams (1996) was the first to suggest that overgeneral autobiographical memory in adults arises in part from early childhood traumatic experiences. According to this author, a child who experienced a trauma may adopt a tendency to recall personal memories at a general rather than specific level. The aim would be to avoid the acute negative affects associated with specific memories potentially related to the trauma. Several studies have provided support for Williams's suggestion, indicating an association between overgeneral memory and (a) trauma during childhood (e.g., Henderson et al., 2002; Kuyken \& Brewin, 1995), (b) diagnosis of posttraumatic stress disorder (e.g., McNally et al., 1995), (c) acute stress disorders (Harvey et al., 1998), and (d) intrusion of traumatic memories (e.g., Hermans et al., 2004). However, some reports showed that depression rather than a history of traumatic experience in childhood may be more predictive of overgeneral autobiographical memory retrieval (e.g., Gibbs \& Rude, 2004; Kuyken, Howell, \& Dalgleish, 2006; Wessel et al., 2001).

Another explanation points to a deficit in the cognitive processes necessary for autobiographical memory retrieval. As evidence for this perspective, a significant negative correlation between IQ and general memories has been found in both depressed and nondepressed adolescents (Park, Goodyer, \& Teasdale, 2002). It has also been reported that overgeneral memory is related to cognitive impairment in the elderly (Phillips \& Williams, 1997; Sampson et al., 2003; Winthorpe \& Rabbitt, 1988). Interestingly, Dalgleish et al. (in press) interpreted overgeneral memory as an indicator of poor task performance in general, possibly as a result of impoverished executive functioning. These authors demonstrated that on a reversed version of the cue word task in which participants were instructed to give overgeneral memories, depressed individuals retrieved more specific memories than controls. However, Wessel, Merckelbach, and Dekkers (2002) failed to show a link between overgeneral memory and cognitive processes. They reported that verbal recall, general learning capacity, and semantic retrieval did not predict autobiographical memory among victims of trauma.

In sum, the origin of the overgeneral retrieval style for depressed individuals is not yet well established. As discussed earlier, although supportive data can be found for both the trauma and the cognitive deficit hypotheses, divergent data have also been reported. A possibly heuristic avenue to determine the origin of overgeneral retrieval style is to investigate its presence in children. In particular, such an approach could establish whether this bias constitutes a vulnerability factor for depression, present before or during the first depressive episodes, or whether it follows from a history of successive depressive episodes or dysthymia.

Another potential benefit of investigating this deficit in childhood is that the investigation would be proximal to one incriminated factor, that is, childhood trauma. The relation between trauma and overgeneral retrieval style might be more apparent in children than in retrospective adults' studies, for several reasons. First, among adults, many interfering historical factors are likely to moderate this relation, because of the temporal distance. Adults may have experienced more events other than the trauma, which might modify autobiographical memory functioning. Second, in adults' studies, trauma is only self-reported and is often not verifiable. Verified reports of trauma are needed to avoid confounding self-reported trauma reflecting psychological vulnerability. Such verifications are possible in children populations for which relevant files exist, such as institutionalized children.

Further, from a clinical perspective, it has been demonstrated that adults with major depressive disorder often have had a history of mood disturbances during childhood (e.g., Wilcox \& Anthony, 2004). Moreover, depressive symptoms in children may be a manifestation of susceptibility for later adult-onset psychiatric disturbances, especially aggression, poor adaptive functioning, and low self-esteem (Aronen \& Stoininen, 2000). Finally, children with major depressive disorder have an increased lifetime risk of suicide (Weissman et al., 1999). Consequently, it is important to identify specific markers in childhood that may lead to (or already be related with) psychiatric disorders, to help clinicians to establish early psychological interventions.

Several studies have explored the relation between emotional symptoms and overgeneral autobiographical memory in adolescents. Park et al. (2002) showed that adolescents (ages 12 to 17 years) with a first depressive disorder retrieved more overgeneral memories than nondepressed controls, as observed in adults. Swales, Williams, and Wood (2001) reported similar results. Orbach, Lamb, Sternberg, Williams, and Dawud-Noursi (2001) observed that adolescents (14 years old on average) with high depressive mood retrieved fewer specific memories than participants with 
low depressive mood. Unfortunately, they did not assess psychiatric diagnosis. In that study, depressive mood was measured by the Children's Depression Inventory (Kovacs, 1992). In addition, Orbach et al. reported that adolescents who had experienced some form of family violence during childhood did not differ from those who had never experienced family violence in their autobiographical memory retrieval. However, that study did not use the Autobiographical Memory Test (Williams \& Broadbent, 1986) to assess autobiographical memory retrieval style. Finally, a recent study (Kuyken et al., 2006) showed that adolescents (ages 12 to 18 years) with major depression exhibited an overgeneral bias. Moreover, this study reported that depressed adolescents reporting a history of trauma retrieved fewer general memories than depressed adolescents reporting no history of trauma.

Only one recent study has explored the relation between autobiographical memory style and emotional symptoms in children. Drummond, Dritschel, Astell, O'Carroll, and Dalgleish (2006) analyzed the effects of age and depressive mood on autobiographical memory recall in children 7 to 11 years old. Results showed a significant link between depressive mood and less specific retrieval of positive memories. In addition, older children (ages 10 to 11 years) recalled more specific memories than younger children (ages 7 to 8 years), irrespective of cue valence. That study therefore suggests that the overgeneral retrieval style might already be present in depressed children. However, this interpretation is limited by the fact that depressive affect was measured using the Children's Depression Inventory (Kovacs, 1992), which reflects a depressive mood rather than a depressive disorder. In addition, that study did not consider a clinical sample of depressed children.

Therefore, to our knowledge, no study has assessed autobiographical memory style in children with a psychiatric diagnosis of depressive disorder. In addition, no study has directly examined the impact of trauma and cognitive processes on overgeneral autobiographical memory bias in children. To go further than merely establishing the deficit in childhood and to provide information about its possible origin, a study should control for many factors (i.e., depressive mood, clinically established depressive disorder, trauma history, and cognitive abilities, especially in the verbal domain). This was the aim of this study.

The first question investigated was whether children (ages 9 to 13 years) with a history of depressive disorder retrieve more general and less specific autobiographical memories than controls. The second question addressed whether depressive mood mediates the potential link between depressive disorder and overgeneral memory. Finally, both explanatory models described previously were tested, examining (a) the impact of the presence of potential traumatic life events and reactions to these events and (b) the role of cognitive processes, as indexed by verbal IQ and verbal memory, on autobiographical memory style.

\section{Method}

\section{Participants}

Clinical sample. Forty children (13 girls and 27 boys) between 9 and 13 years of age $(M=11.5)$ were recruited from two institutions for children with special educational needs. In the Belgian system, such institutions are in charge of children with cognitive, psychological, or familial difficulties. Children with psychotic disorder (assessed using the Schedule for Affective Disorder and Schizophrenia for Children [K-SADS-PL]) or moderate to serious mental retardation-namely those with total IQ under 50/55 (Diagnostic and Statistical Manual of Mental Disorders, 4th ed. [DSM-IV]; American Psychiatric Association, 1994)—were excluded from the experiment.

The clinical sample was divided in two subgroups: the depressed clinical group (DCG; $n=15$ ) included children who met criteria for a $D S M-I V$ lifetime depressive disorder (dysthymia, minor depressive disorder, or nonspecific depressive disorder); the never depressed clinical group (nDCG; $n=25$ ) included children with no history of depressive disorder but who met criteria for other lifetime psychiatric disorders (anxiety or behavioral disorders). Psychiatric disorders were assessed using the K-SADS-PL, which is described in the Measures section. When a doubt arose regarding the diagnosis of participants, a consensus was found between the experimenter and a psychologist specialized in therapy for children.

Among DCG children, (a) 11 had a current diagnosis of depressive disorder, of which 4 presented a comorbid lifetime diagnosis of anxiety disorder (general anxiety disorder, posttraumatic stress disorder, agoraphobia, or a combination of these), 2 had a comorbid lifetime behavioral disorder (attention deficit hyperactivity, oppositional defiant disorder, conduct disorder, or a combination of these), and 2 presented both comorbid lifetime anxiety and behavioral disorder; (b) 4 were in remission from depression, of which 3 presented a lifetime behavioral disorder and 1 had a lifetime anxiety disorder.

Among nDCG children, 17 had a lifetime behavioral disorder (attention deficit, attention deficit hyperactivity, oppositional defiant disorder, conduct disorder, or a combination of these), and 3 presented a lifetime anxiety disorder (general anxiety or posttraumatic stress disorder). Five children presented emotional symptoms that did not meet DSM-IV criteria for a psychiatric disorder. 
Control sample. A sample of 23 control children ( 8 girls and 15 boys), ages 9 to 12 years, was recruited from a community primary school. Three participants were excluded from the experiment. One child was not a native French speaker, and two had potential psychiatric disorders. The remaining 20, 7 girls and 13 boys $(M=11.3)$, took part in the experiment and constituted the control group (CG). All were free of a history of psychiatric disorder according to $D S M-I V$ criteria, as assessed with the K-SADS-PL. The control and clinical groups were balanced for age and gender.

\section{Measures}

Autobiographical memory. The procedure and coding scheme used for the Autobiographical Memory Test followed Williams and Broadbent (1986). The French adult version of Williams's Autobiographical Memory Test was developed by Neumann and Philippot (2006) and was adapted for children by Laroche (2004). Five positive (list A: happy, glad, friendly, tender, reassured; list B: joyful, luck, easy, smile, friend), five negative (list A: fail, sluggish, regret, discouraged, stupidity; list B: sad, disagreeable, naughty, not fun, tired), and five neutral words (list A: grass, music, carrot, book, purchase; list B: fast, pianist, bath, illness, uncle) were presented orally to the participant. The two parallel sets of words used were matched for emotional valence and word frequency. The children were instructed (a) to give a specific memory to each cue word (i.e., a memory of a particular event that happened to them once and that did not last more than $24 \mathrm{hrs}$ ) and (b) not to give the same memory to more than one cue word. In addition, the children were informed that the event could be important or common and that it could have happened recently or a long time ago. Participants were given $30 \mathrm{sec}$ to recall a specific personal memory in response to each cue word. They had an opportunity to practice with several cue words with feedback. Before the test began, participants needed to retrieve at least one specific memory.

Each memory retrieved was coded on specificity. First responses were categorized as (a) specific, if they were memories of events occurring at a particular place and time and lasting less than a day; (b) generic, if they were summaries of repeated events; (c) extended, if they were memories of an event lasting longer than a day; or (d) a nonresponse, if the child failed to give a memory within the 30 -sec time limit. A stopwatch was used to measure latency before every recall. All responses were recorded on audiotape for later coding on specificity.

Verbal IQ. Two subtests of the Wechsler Intelligence Scale for Children-Third Edition (Wechsler, 1991), Vocabulary and Similarity, were used to estimate verbal intelligence. Gregoire, Penhouet, and Boy
(1996) showed that the French version of the Wechsler Intelligence Scale for Children-Third Edition has good internal consistency, with a Cronbach's alpha value of 0.94 . Moreover, the Vocabulary and Similarity subtests have shown acceptable reliability coefficients of 0.86 and 0.75 , respectively, as well as good interrater agreement of 0.98 and 0.85 , respectively (Wechsler, 1991). The Vocabulary subtest measures word knowledge and verbal fluency (i.e., language ability). Words were presented orally to the children, and they were invited to explain the meaning of each word. The Similarity subtest evaluates abstract reasoning and relations (i.e., comprehension capacity). Pairs of words were presented orally to the participants (e.g., blue and red), and they were told to explain what was common between each pair of words (in the previous example the participant could reply "blue and red are two colors"). Numbers of correct responses were summed for each subtest and were standardized $(M=10, S D=3)$.

Verbal memory. The Stories subtest of the Child Memory Scale (Cohen, 2001) was used to measure immediate verbal memory. The Child Memory Scale is designed for children and adolescents ages 5 to 16 years. The Stories subtest was found to have a high internal consistency (Cronbach's $\alpha=0.94$ ) as well as a high interrater agreement (0.99). Two short stories are normally read to the child, but only one story was read in this study because of time constraints. Immediately after the story's reading, the participant was invited to retell the story as precisely as possible. Number of units and themes recalled were summed and standardized $(M=10, S D=3)$.

Psychopathology. All participants were interviewed using the K-SADS-PL (Kaufman et al., 1997; translation in French by Mouren-Siméoni, 2002). The $\mathrm{K}-\mathrm{SADS}-\mathrm{PL}$ is a semistructured interview of psychopathology for children and adolescents ages 6 to 17 years and is designed to obtain information about all lifetime major psychiatric disorders according to $D S M-I V$ diagnostic criteria. The K-SADS-PL has been widely used in family (e.g., Puig-Antich et al., 1989) and clinical studies (e.g., Park et al., 2002). The English version of this interview has shown good internal reliability for depressive disorders (Kaufman et al., 1997). Moreover, test-retest and interrater agreement (0.79) were reported to be acceptable for all diagnoses (Chambers et al., 1985). Typically, both parents and child must complete the K-SADS-PL separately. In this study, only the children completed the test. However, it has been demonstrated that children are usually more aware than their parents of their affective symptoms such as depression and are thus more accurate informants (Costello, 1996). 
Potential traumatic life events. First, a list of potential traumatic life events was designed on the basis of the K-SADS-PL (i.e., physical and sexual abuse, interparental violence, caregiver's death, serious accident, fire, natural disaster, assault, and witness to murder). As noted previously, the K-SADS-PL has been shown to have good psychometric properties (Kaufman et al., 1997). Second, several life events reported by the participants were added to this list: emotional neglect, parents' divorce, alcoholic- or drug-addicted parent, and adoption. Participants were asked during the interview whether they had experienced any of those events in their life. Their answers were checked by consulting children's files (for the clinical sample only) or questioning school or institution educators. The total number of potential traumatic life events was coded.

In addition, the number of posttraumatic reactions was assessed for participants who experienced an event considered to be potentially traumatic by criteria of the $D S M-I V$ or listed in the K-SADS-PL (i.e., an event during which the risk of death or serious injury was present). Five reactions commonly associated with posttraumatic stress disorder in childhood were measured: (a) intrusion of the event (e.g., thoughts, images), (b) attempts to avoid the event (and thoughts, images, emotions associated), (c) frequent nightmares, (d) sleeping troubles, and (e) irritability. A score between 0 (no stress reaction) and 5 (five stress reactions) was given by computing the sum of the number of posttraumatic reactions reported.

Depressive mood. The Multiscore Depression Inventory for Children (MDI-C, Berndt \& Kaiser, 1996; translation in French, 1999) is a 79-item self-report measure of depressive symptoms, suited for children and adolescents ages 8 to 17 years. The MDI-C was adapted from the adult version (Berndt, 1986). Internal consistency for the total score was reported to be good, with a Cronbach's alpha of 0.92 (Berndt \& Kaiser, 1999). Moreover, the MDI-C is complete and covers eight subscales: Anxiety (physical and cognitive aspects), Self-Esteem (child's perception of him or herself), Sad Mood (child's affective state), Instrumental Helplessness (child's perception of his or her capacity to cope with social situations), Social Introversion (child's tendency to withdraw into him or herself in social situations), Low Energy (intensity of cognitive and physical capacities), Pessimism (child's perception of his or her future), and Defiance (behavioral problems). Factorial analysis confirmed an eight-factor structure (Berndt \& Kaiser, 1999). The children were instructed to respond true or false to each item.

\section{Procedure}

All aspects of the procedure complied to American Psychological Association (2005) ethical principles re- garding research with human participants. After obtaining permission to conduct the study from the proper authorities (i.e., institution or school directors and educational teams or teachers), the study was explained to the parents. About $75 \%$ of the parents gave their written informed consent. We then presented the study to the children and asked them whether they agreed to participate. Children were informed about the confidentiality of their answers and about their right to stop the experiment anytime without having to give any reason. All children provided their assent.

Due to their psychological condition, the procedure was split into two or three sessions for clinical participants, whereas only one session was needed for CG children. Each session lasted between 30 and $60 \mathrm{~min}$ and took place in a quiet room of the child's institution or school. The first session was devoted to the assessment of autobiographical memory, verbal IQ, and verbal memory. Assessment of psychopathology was achieved during the second and sometimes third session. Consequently, autobiographical memory style was assessed without knowing the psychiatric status of the children. Participants were asked to complete the MDI-C between the first and the last session (after the unique session for CG participants). The understanding of $10 \mathrm{MDI}-\mathrm{C}$ items, as well as of all reverse items, was checked orally at the beginning of the second session, in particular for clinical participants who had a low verbal IQ. If any problem was detected, all items were orally checked by the experimenter. Finally, participants were thanked for their collaboration, fully debriefed, and invited to ask questions about the study.

\section{Results}

\section{Descriptive Statistics}

The gender ratio and the mean age, verbal IQ, verbal memory, potential traumatic life events, posttraumatic reactions, and depressive mood of the three groups are reported in Table 1 . Table 2 shows the number of children who experienced each potential traumatic life events listed, as a function of group. Chisquare analyses revealed no significant differences in gender ratio among the three groups, $\chi^{2}(2)=2.20, p=$ $n s$. A simple factorial analysis of variance (ANOVA) showed no group differences in age, $F(2,57)=1.29$, $p=n$ s. In contrast, results from simple factorial ANOVAs indicated a main effect of group on verbal IQ, $F(2,57)=16.11, p<.001, \eta^{2}=.36$; verbal memory, $F(2,57)=15.08, p<.001, \eta^{2}=.35$; number of potential traumatic life events, $F(2,57)=35.09, p<.001$, $\eta^{2}=.55$; number of posttraumatic reactions, $F(2,23)=$ $5.37, p<.05, \eta^{2}=.18$; and depressive mood, $F(2,55)=$ $26.15, p<.001, \eta^{2}=.49$. Post hoc comparisons using the Bonferroni procedure were performed. Table 1 
VRIELYNCK, DEPLUS, PHILIPPOT

Table 1. Means and Standard Deviations of Descriptive Statistics as a Function of Group

\begin{tabular}{|c|c|c|c|c|c|c|c|c|c|c|c|c|}
\hline & \multicolumn{8}{|c|}{ Clinical Sample } & & & & \\
\hline & \multicolumn{4}{|c|}{ Depressed $^{\mathrm{a}}$} & \multicolumn{4}{|c|}{ Never Depressed ${ }^{b}$} & \multicolumn{4}{|c|}{ Control Sample ${ }^{c}$} \\
\hline & $n$ & $\%$ & $M$ & $S D$ & $n$ & $\%$ & $M$ & $S D$ & $n$ & $\%$ & $M$ & $S D$ \\
\hline Male & 8 & 53 & & & 19 & 76 & & & 13 & 65 & & \\
\hline Female & 7 & 47 & & & 6 & 24 & & & 7 & 35 & & \\
\hline Age & & & 11.90 & 1.23 & & & 11.40 & 1.04 & & & 11.50 & 0.87 \\
\hline Verbal IQ & & & $5.45_{\mathrm{b}}$ & 3.05 & & & $6.25 b$ & 3.22 & & & $10.42_{\mathrm{a}}$ & 2.73 \\
\hline Verbal Memory & & & $5.86_{\mathrm{b}}$ & 3.10 & & & $5.50_{\mathrm{b}}$ & 3.44 & & & $10.57 \mathrm{a}$ & 3.73 \\
\hline Potential Traumatic Life Events & & & $4.33_{\mathrm{a}}$ & 1.67 & & & $2.20_{\mathrm{b}}$ & 1.53 & & & $0.50_{\mathrm{c}}$ & 0.61 \\
\hline Posttraumatic Reactions & & & $3.15_{\mathrm{a}}$ & 1.40 & & & $1.61_{\mathrm{b}}$ & 1.94 & & & - & - \\
\hline Depressive Mood & & & $60.64 \mathrm{a}$ & 9.28 & & & $55.24_{\mathrm{a}}$ & 6.20 & & & $42.00_{\mathrm{b}}$ & 8.59 \\
\hline
\end{tabular}

Note: Mean differences between groups are shown by different subscripts, $a$ indicating the highest score and $c$ the lowest score.

${ }^{\mathrm{a}} n=15 . \mathrm{b}_{n}=25 .{ }^{\mathrm{c}} n=20$.

Table 2. Number of Children by Life Event Experienced as a Function of Group

\begin{tabular}{lccc}
\hline & \multicolumn{2}{c}{ Clinical Sample } & \\
\cline { 2 - 3 } & Depressed $^{\mathbf{a}}$ & $\begin{array}{c}\text { Never } \\
\text { Depressed }^{\mathbf{b}}\end{array}$ & $\begin{array}{c}\text { Control } \\
\text { Sample }^{\mathbf{c}}\end{array}$ \\
\hline Physical Abuse & 7 & 3 & 0 \\
Sexual Abuse & 5 & 2 & 0 \\
Interparental Violence & 12 & 4 & 0 \\
Caregiver's Death & 6 & 3 & 1 \\
Serious Accident & 1 & 1 & 1 \\
Fire & 2 & 3 & 0 \\
Natural Disaster & 0 & 0 & 0 \\
Assault & 0 & 0 & 0 \\
Witness to Murder & 2 & 1 & 0 \\
Emotional Abuse & 11 & 10 & 0 \\
Parent's Divorce & 15 & 18 & 7 \\
Alcoholic or Drug & 6 & 5 & 0 \\
$\quad$ Addicted Parent & & 1 & 0 \\
Adoption & 1 & & \\
\hline
\end{tabular}

${ }^{\mathrm{a}} n=20 .{ }^{\mathrm{b}} n=15 .{ }^{\mathrm{c}} n=25$.

shows differences among the three groups on these variables. CG obtained higher scores of verbal IQ and verbal memory than clinical samples (DCG and nDCG). DCG experienced more potential traumatic life events than $\mathrm{nDCG}$, who in turn experienced more potential traumatic life events than CG. DCG reported more posttraumatic reactions than nDCG. Finally, both clinical samples, depressed and never depressed, had higher depressive mood than CG.

\section{Effects of Depressive Disorder on Autobiographical Memory}

A three-way ANOVA with Group (DCG, nDCG, $\mathrm{CG}$ ), Memory Type (specific, generic, extended, and nonresponse), and Cue Valence (positive, negative, and neutral) was conducted. This analysis revealed a Group $\times$ Memory Type interaction, $F(6,168)=13.87, p<$ $.001, \eta^{2}=.32$. There were no effects of or interactions with cue valence.
To examine the effect of group on memory type, a multivariate ANOVA was computed with group as the independent variable and memory types as the dependent variables. Table 3 shows the means of memory types retrieved by group. There was a significant effect of group on specific, $F(2,57)=21.11, p<.001, \eta^{2}=$ .42 ; generic, $F(2,57)=9.05, p<.001, \eta^{2}=.24$; and extended memories, $F(2,57)=3.94, p<.05, \eta^{2}=.12$; as well as on nonresponses, $F(2,57)=5.54, p<.05, \eta^{2}=$ .16. Post hoc analyses using the Bonferroni procedure were performed to compare the groups. Table 3 indicates significant differences among the three groups (see subscripts). The results showed that DCG retrieved less specific memories than $\mathrm{nDCG}$, who in turn recalled less specific memories than CG. Second, DCG and $\mathrm{nDCG}$ recalled more generic memories than CG. Third, DCG retrieved more extended memories than CG. Finally, DCG gave more nonresponses than nDCG and CG.

\section{Correlations Among Potential Mediator Variables and Memory Type}

Correlations were computed to examine the links among verbal IQ, verbal memory, potential traumatic life events, posttraumatic reactions, depressive mood, and the type of memory retrieved (see Table 4). As can be seen, the number of specific memories was correlated with all of these variables. The number of generic memories was correlated with verbal IQ, verbal memory, and potential traumatic life events. The number of extended memories was correlated with potential traumatic life events and depressive mood. Finally, the number of nonresponses was correlated with verbal IQ and verbal memory.

\section{Influence of Mediator Variables}

A stepwise regression model was conducted on specific and generic memories separately (see Table 5). We decided not to account for extended memories 
AUTOBIOGRAPHICAL MEMORY IN CHILDREN

Table 3. Mean Numbers and Standard Deviations of Different Memory Types Retrieved as a Function of Group

\begin{tabular}{|c|c|c|c|c|c|c|}
\hline & \multicolumn{4}{|c|}{ Clinical Sample } & & \\
\hline & \multicolumn{2}{|c|}{ Depressed } & \multicolumn{2}{|c|}{ Never Depressed } & \multicolumn{2}{|c|}{ Control Sample } \\
\hline & $M$ & $S D$ & $M$ & $S D$ & $M$ & $S D$ \\
\hline Specific & $7.13_{\mathrm{c}}$ & 2.67 & $10.00_{\mathrm{b}}$ & 2.45 & $12.10_{\mathrm{a}}$ & 1.48 \\
\hline Generic & $4.00_{\mathrm{a}}$ & 2.03 & $2.88 \mathrm{a}$ & 1.85 & $1.55_{\mathrm{b}}$ & 1.14 \\
\hline Extended & $1.00_{\mathrm{a}}$ & 0.75 & 0.56 & 0.77 & $0.35_{\mathrm{b}}$ & 0.49 \\
\hline Nonresponses & $2.87 \mathrm{a}$ & 1.99 & $1.56_{\mathrm{b}}$ & 1.80 & $1.00_{\mathrm{b}}$ & 1.12 \\
\hline
\end{tabular}

Note: Mean differences between groups are shown by different subscripts, $a$ indicating the highest score and $c$ the lowest score. ${ }^{\mathrm{a}} n=15 .{ }^{\mathrm{b}} n=15 .{ }^{\mathrm{c}} n=25$.

Table 4. Correlations Between Potential Mediator Variables and Memory Types

\begin{tabular}{|c|c|c|c|c|c|c|c|c|c|}
\hline & IQ & VM & PTLE & PTR $^{\mathbf{a}}$ & $\mathbf{D M}^{\mathbf{b}}$ & SM & GM & EM & NR \\
\hline IQ & & $.62 * *$ & $-.40^{*}$ & -.23 & $-.54 * *$ & $.46^{* * *}$ & $-.30 *$ & -.14 & $-.36^{* *}$ \\
\hline VM & & - & $-.32 *$ & .07 & $-.41 * *$ & $.53 * *$ & $-.39 * *$ & -.06 & $-.41 * *$ \\
\hline PTLE & & & - & $.42 * *$ & $.54 * *$ & $-.37 * *$ & $.31 *$ & $.26^{*}$ & .16 \\
\hline PTR & & & & - & .24 & -.24 & .11 & .28 & .14 \\
\hline $\mathrm{DM}^{\mathrm{b}}$ & & & & & - & $-.37 * *$ & .25 & $.39 * *$ & .17 \\
\hline SM & & & & & & - & $-.73 * *$ & $-.35^{* *}$ & $-.70^{* *}$ \\
\hline GM & & & & & & & - & .05 & .08 \\
\hline EM & & & & & & & & - & .12 \\
\hline NR & & & & & & & & & - \\
\hline
\end{tabular}

Note: $N=60 . \mathrm{IQ}=$ verbal IQ; $\mathrm{VM}=$ verbal memory; PTLE = potential traumatic life events; PTR = posttraumatic reactions; $\mathrm{DM}=$ depressive mood, $\mathrm{SM}=$ specific memories, $\mathrm{GM}=$ generic memories; $\mathrm{EM}=$ extended memories; $\mathrm{NR}=$ nonresponses.

${ }^{\mathrm{a}} n=26 .{ }^{\mathrm{b}}$ Two missing values.

$* p<.05$. ** $p<.01$.

Table 5. Regression Analyses Predicting the Number of Specific and Generic Memories Retrieved

\begin{tabular}{|c|c|c|c|c|c|c|}
\hline \multirow[b]{2}{*}{ Variable } & \multicolumn{3}{|c|}{ Specific Memories } & \multicolumn{3}{|c|}{ Generic Memories } \\
\hline & $\boldsymbol{B}$ & $S E B$ & $\beta$ & $B$ & $S E B$ & $\beta$ \\
\hline \multicolumn{7}{|l|}{ Step 1} \\
\hline Group & 1.31 & .22 & $.59 *$ & -0.59 & .17 & $-.40 *$ \\
\hline \multicolumn{7}{|l|}{ Step 2} \\
\hline Group & 1.27 & .24 & $.57 *$ & -0.58 & .19 & $-.39 *$ \\
\hline IQ & 0.71 & .51 & .17 & -0.01 & .04 & -.03 \\
\hline \multicolumn{7}{|l|}{ Step 2} \\
\hline Group & 1.11 & .22 & $.50 *$ & -0.52 & .17 & $-.35^{*}$ \\
\hline VM & 0.13 & .04 & $.36^{*}$ & -0.05 & .03 & -.23 \\
\hline \multicolumn{7}{|l|}{ Step 2} \\
\hline Group & 1.67 & .31 & $.75^{*}$ & -0.70 & .24 & $-.48 *$ \\
\hline PTLE & 0.36 & .22 & .25 & -0.11 & .17 & -.11 \\
\hline \multicolumn{7}{|l|}{ Step 2} \\
\hline Group & 1.42 & .28 & $.63^{*}$ & -0.71 & .21 & $-.48^{*}$ \\
\hline DM & 0.02 & .04 & .09 & -0.03 & .03 & -.15 \\
\hline
\end{tabular}

Note: $N=60$. Group $=$ the contrast between the depressed clinical group and the two other groups; IQ = verbal IQ; VM = verbal memory; PTLE = potential traumatic life events; $\mathrm{DM}=$ depressive mood. $* p<.01$.

and nonresponses because of their low response frequency. Group was entered in a first step. A priori comparisons using contrast codes were performed to deconstruct the overall effect of group. Verbal IQ, verbal memory, potential traumatic life events, and depressive mood were added separately in a second step. The aim was to investigate the potential additive effect on variance in specific and generic memories. Group (i.e., the contrast between DCG and the two other groups) accounted for significant variance in number of specific memories, $F(2,57)=21.11, p<$ .001 , adjusted $R^{2}=.42$. The inclusion of verbal memory performance resulted in a significant additional $9 \%$ of variance explained in number of specific memories, $F(3,56)=19.599, p<.001$, adjusted $R^{2}=.51$. Other variables did not add significantly to this variance. It should be noted that entering the group after the potential mediators did not alter the pattern of results.

\section{Discussion}

This study is the first to examine whether an overgeneral autobiographical memory bias is already present in children with a diagnosis of depressive disorder. The results demonstrate a clear effect of lifetime depressive disorder on overgeneral memory. Indeed, children with a lifetime depressive disorder recalled significantly fewer specific and more generic memories than children with no psychiatric disorder, irrespective of cue valence. Furthermore, compared to children with no depressive but other psychiatric disorders and with a similar difficult history of development, participants 
with depressive disorder also recalled significantly fewer specific memories. This last result suggests that the overgeneral bias cannot be explained by only a general psychiatric status or a difficult history of development. This study replicates findings reported among adults (reviewed by van Vreeswijk \& de Wilde, 2004) and adolescents (e.g., Park et al., 2002).

Moreover, results indicate that depressive mood does not mediate the effect of lifetime depression on overgeneral memory, even if depressive mood correlated with less specific memories retrieved. This finding is in line with previous reports that overgeneral retrieval is a stable cognitive marker of vulnerability to depression, rather than a marker of current depression (e.g., Brittlebank et al., 1993; Gibbs \& Rude, 2004; Mackinger et al., 2000), as explained in the introduction.

This study also tested two potential explanations regarding the origin of overgeneral memory. First, our results do not support the notion that childhood trauma accounts for the emergence of the overgeneral bias (Williams, 1996). Indeed, when the number of potential traumatic life events was controlled for, the effect of depressive disorder on specific and generic memories was still significant. Still, children with depressive disorder experienced more potential traumatic life events than other participants. Our observation is consistent with several studies (e.g., Gibbs \& Rude, 2004; Kuyken et al., 2006; Orbach et al., 2001; Wessel et al., 2001). However, it should be noted that others reported significant relations between the presence of childhood trauma and overgeneral autobiographical memory (e.g., Henderson et al., 2002; Kuyken \& Brewin, 1995). In addition, our results indicate that the number of posttraumatic reactions is not correlated with the type of memories retrieved, although this might have been due to the relatively low number of children diagnosed with posttraumatic stress disorder (i.e., 7).

Perhaps the incongruence among studies regarding both the presence and the subjective impact of childhood trauma is due to different methodological approaches. First, several studies reporting a relation between trauma and overgeneral memory did not assess the presence of depressive disorder (e.g., Harvey et al., 1998; Henderson et al., 2002; McNally et al., 1995). It may be that, in these studies, a current or past diagnosis of depressive disorder was mediating the association between traumatic experiences and overgeneral memory. From this perspective, the overgenerality bias would not be directly related to traumatic experiences but to depression, which might result, among other factors, from traumatic experiences. Second, some authors have examined the impact of a single type of serious traumatic event (e.g., sexual abuse; Henderson et al., 2002; Kuyken \& Brewin, 1995; or physical abuse; Hermans et al., 2004) on overgeneral memory. Alter- natively, this study, as well as Gibbs and Rude (2004) and Wessel et al. (2001), measured a level of childhood trauma that accounted for several types of stressful life events and their additive effect (see Table 2). This methodological difference might account for the observed difference in results.

The second potential explanation for overgeneral memory assessed by this study is the role of cognitive processes, as indexed by verbal IQ and verbal memory. This finding does not support the notion that overgenerality is merely the result of a cognitive impairment, as reported in other studies (e.g., Dalgleish et al., in press; Phillips \& Williams, 1997). Indeed, our results show that the effect of depressive disorder on overgeneral retrieval is significant, even after controlling for verbal IQ and verbal memory. Nevertheless, verbal memory explains an additive part of the variance of specific memories retrieved. This suggests that verbal cognitive processes should be examined in studies analyzing autobiographical memory style. It is difficult to compare results from this study with the literature because of the diversity of cognitive processes examined in different studies. Some authors have assessed a general cognitive impairment (e.g., Phillips \& Williams, 1997) or a total IQ (e.g., Park et al, 2002; Sampson et al., 2003; Wessel et al., 2001), whereas others have measured more specific cognitive processes (e.g., semantic fluency; Wessel et al., 2001), immediate memory (Wessel et al., 2001), or working memory (Dalgleish et al., in press; Winthorpe \& Rabbitt, 1988).

In summary, this study is the first to document that children with a lifetime depressive disorder are characterized by an overgeneral autobiographical memory, not mediated by self-reported depressive mood. This deficit seems to be not merely a general marker of psychopathology, as it is much weaker in children presenting other psychiatric diagnoses, such as behavioral or anxiety disorders. Furthermore, our results suggest that potential traumatic life events as well as verbal cognitive processes cannot fully explain the origin of this overgeneral bias. Verbal memory capacity seems to influence the specificity of autobiographical memory but is not sufficient to fully explain the effect of depressive disorder on this overgeneral bias.

This study has some limitations. First, the interpretations and their generalization are tempered by the relatively modest sample size of this study. Second, a measure of executive capacities would have improved the understanding of our data. However, the participants in this study had already undergone heavy testing, and we were forced to make strategic choices. We opted for testing the processes that were more closely related to autobiographical memory and emotion regulation, both in the empirical literature 
(e.g., Park et al., 2002; Wessel et al., 2001) and on logical grounds.

Moreover, developmental factors, which were not analyzed in this study, might influence autobiographical memory style in children. Parents and children talk together about experienced events as soon as the child starts to speak. From 4 or 5 years old, the child is able to consider him or herself as the author of experiences and describes them to adults. Young children's preferred mode of autobiographical memory is general (Nelson, 1993). Children retrieve more detailed and specific memories with increasing age (Howe \& Courage, 1997). A wealth of studies have highlighted the role of interaction between parents and children in this development of autobiographical memory (e.g., Hudson, 1990; Nelson, 1993; Reese \& Fivush, 1993). For example, it was reported that when mothers gave precise information about past experiences, their children were able to recall more specific memories (e.g., Engel, 1986). Furthermore, Fivush (1991) observed that when mothers gave a more emotional narrative, their child retrieved more emotional information 14 months afterward. Future studies might take into account this developmental literature.

This study has a number of clinical implications. First, the link between overgeneral memory and psychopathological processes, in particular rumination, should be examined in children, as it was demonstrated in adults (e.g., Goddard et al., 1996). Indeed, it is probable that the overgeneral bias predicts rumination, a cognitive marker that in turn may lead to depressive disorder (Nolen-Hoeksema, 2000). Second, identifying this overgeneral bias in childhood may help clinicians to identify children who are vulnerable to depressive disorders and to thereby utilize early interventions. In adults, mindfulness-based cognitive therapy was reported to reduce overgeneral memory (Williams, Teasdale, Segal, \& Soulsby, 2000). The goal of this therapy is to increase awareness of present experience and, as a consequence, to reduce rumination. Future research will need to determine to what extent this form of cognitive therapy, based on attentional control, might be adapted to children. Finally, longitudinal studies are required to examine if improving autobiographical specificity during childhood might prevent the emergence of depressive disorder or decrease the intensity of depressive symptoms.

\section{References}

American Psychiatric Association. (1994). Diagnostic and statistical manual of mental disorders (4th ed.). Washington, DC: Author.

American Psychological Association. (2005). Publication manual of the American Psychological Association (5th ed.). Washington, DC: Author.
Aronen, E. T., \& Stoininen, M. (2000). Childhood depressive symptoms predict psychiatric problems in young adults. Canadian Journal of Psychiatry, 45, 465-470.

Berndt, D. J. (1986). Multiscore Depression Inventory (MDI) manual. Los Angeles: Western Psychological Services.

Berndt, D. J., \& Kaiser, C. F. (1996). Children's Multiscore Depression Inventory. Los Angeles: Western Psychological Services.

Berndt, D. J., \& Kaiser, C. F. (1999). Echelle Composite de Depression pour Enfant [Children's Multiscore Depression Inventory]. Paris: Les Editions du Centre de Psychologie Appliquée.

Brittlebank, A. D., Scott, J., Williams, J. M. G., \& Ferrier, I. N. (1993). Autobiographical memory in depression: State or trait marker? British Journal of Psychiatry, 162, 118-121.

Burke, M., \& Matthews, A. (1992). Autobiographical memory and clinical anxiety. Cognition and Emotion, 6, 23-35.

Chambers, W., Puig-Antich, J., Hirsch, M., Ambrosini, P.-J., Tabrizi, M.-A., \& Davies, M. (1985). Assessment of affective disorders in children and adolescents by semi-structured interview: testretest reliability of the Kiddie-SADS-P. Archives of General Psychiatry, 42, 696-702.

Cohen, M. J. (2001). Echelle de mémoire pour enfants [Memory scale for children]. Paris: ECPA.

Conway, M. A., \& Pleydell-Pearce, C. W. (2000). The construction of autobiographical memories in the self-memory system. Psychological Review, 107, 261-288.

Costello, A. J. (1996). Assessment and diagnosis of affective disorders in children. Journal of Child Psychology \& Psychiatry, 27, 565-574.

Dalgleish, T., Perkins, N., Williams, J. M. G., Golden, A-M. J., Barnard, P. J., Au-Yeung, C., et al. (in press). Reduced specificity of autobiographical memory and depression: The role of executive processes. Journal of Experimental Psychology: General.

Dalgleish, T., Tchanturia, K., Serpell, L., Hems, S., Yiend, J., De Silva, P., et al. (2003). Self-reported parental abuse relates to autobiographical memory style in patients with eating disorders. Emotion, 3, 211-222.

Drummond, L. E., Dritschel, B., Astell, A., O'Carroll, R. E., \& Dalgleish, T. (2006). Effects of age, dysphoria and emotion-focusing on autobiographical memory specificity in children. Cognition and Emotion, 20, 488-505.

Engel, S. (1986). Learning to reminisce: A developmental study of how young children talk about the past. Unpublished doctoral dissertation, City University of New York.

Evans, J., Williams, J. M. G., O’Loughlin, S., \& Howells, K. (1992). Autobiographical memory and problem-solving strategies of parasuicide patients. Psychological Medicine, 22, 399-405.

Fivush, R. (1991).Gender and emotion in mother-child conversation about the past. Journal of Narrative and Life History, 1, 325-341.

Gibbs, B. R., \& Rude, S. S. (2004). Overgeneral autobiographical memory as depression vulnerability. Cognitive Therapy and Research, 28, 511-526.

Goddard, L., Dritschel, B., \& Burton, A. (1996). Role of autobiographical memory in social problem solving and depression. Journal of Abnormal Psychology, 105, 609-616.

Gregoire, J., Penhouet, C., \& Boy, T. (1996). L'adaptation française de l'échelle de Wechsler pour enfants, version III [French adaptation of Wechsler Scale for Children, third version]. L'Orientation Scolaire et Professionnelle, 25, 489-506.

Harvey, A. G., Bryant, R. A., \& Dang, S. T. (1998). Autobiographical memory in acute stress disorder. Journal of Consulting \& Clinical Psychology, 66, 500-506.

Henderson, D., Hargreaves, I., Gregory, S., \& Williams, J. M. G. (2002). Autobiographical memory and emotion in a non-clini- 
cal sample of women with and without a reported history of childhood sexual abuse. British Journal of Clinical Psychology, $41,129-141$.

Hermans, D., van den Broeck, K., Belis, G., Raes, F., Pieters, G., \& Eelen, P. (2004). Trauma and autobiographical memory specificity in depressed inpatients. Behaviour Research and Therapy, 42, 775-789.

Howe, M. L., \& Courage, M. L. (1997). The emergence and early development of autobiographical memory. Psychological Review, 104, 499-523.

Hudson, J. A. (1990). Constructive processing in children's event memory. Developmental Psychology, 26, 180-187.

Kaufman, J., Birmaher, B., Brent, D., Rao, U., Flynn, C., Moreci, P., et al. (1997). Schedule for Affective Disorder and Schizophrenia for School-Age Children-Present and Lifetime Version (K-SADS-PL): Initial reliability and validity data. Journal of the American Academy of Child \& Adolescent Psychiatry, 36, 980-988.

Kovacs, M. (1992). Children's Depression Inventory. New York: Multi-Health Systems.

Kuyken, W., \& Brewin, C. R. (1995). Autobiographical memory functioning in depression and reports of early abuse. Journal of Abnormal Psychology, 104, 585-591.

Kuyken, W., Howell, R., \& Dalgleish, T. (2006). Overgeneral autobiographical memory in depressed adolescents with versus without a reported history of trauma. Journal of Abnormal Psychology, 115, 387-396.

Laberg, S., \& Andersson, X. (2004). Autobiographical memories in patients treated for bulimia nervosa. European Eating Disorders Review, 12, 34-41.

Laroche, H. (2004). Effet d'un vécu traumatique et de l'âge sur la spécificité des souvenirs autobiographiques [Effect of traumatic experience and age on the specificity of autobiographical memories]. Unpublished manuscript, University of Louvain, Belgium.

Mackinger, H. F., Pachinger, M. M., Leibetseder, M. M., \& Fartacek, R. R. (2000). Autobiographical memories in women remitted from major depression. Journal of Abnormal Psychology, 109, 331-334.

McNally, R. J., Lasko, N. B. Macklin, M. L., \& Pitman, R. K. (1995). Autobiographical memory disturbance in combat-related posttraumatic stress disorder. Behaviour Research and Therapy, 33, $619-630$

Moffitt, K. H., Singer, J. A., Nelligan, D. W., Carlson, M. A., \& Vyse, S. A. (1994). Depression and memory narrative type. Journal of Abnormal Psychology, 103, 581-583.

Mouren-Siméoni, M. C. (Ed.). (2002). Kiddie-SADS version vie entière (K-SADS-PL) 6-18 ans. Traduction française [Kiddie-SADS Lifetime Version for 6-18 years old. French translation]. Paris: Institut national de la Santé et de la Recherche Médicale.

Nandrino, J. L., Pezard, L., Poste, A., Reveillere, C., \& Beaune, D. (2002). Autobiographical memory in major depression: A comparison between first-episode and recurrent patients. Psychopathology, 35, 335-340.

Nelson, K. (1993). The psychological and social origins of autobiographical memory. Psychological Sciences, 4, 7-14.

Neumann, A., \& Philippot, P. (2006). Test de mémoire autobiographique: Présentation et validation [Autobiographical Memory Test: Presentation and validation]. Manuscript in preparation.

Nolen-Hoeksema, S. (2000). The role of rumination in depressive disorders and mixed anxiety/depressive symptoms. Journal of Abnormal Psychology, 109, 504-511.

Orbach, Y., Lamb, M. E., Sternberg, K. J., Williams, J. M. G., \& Dawud-Noursi, S. (2001). The effects of being a victim or wit- ness of family violence on the retrieval of autobiographical memories. Child Abuse \& Neglect, 25, 1427-1437.

Park, R. J., Goodyer, I. M., \& Teasdale, J. D. (2002). Categoric overgeneral autobiographical memory in adolescents with major depressive disorder. Psychological Medicine, 32, 267-276.

Phillips, S., \& Williams, J. M. G. (1997). Cognitive impairment, depression and the specificity of autobiographical memory in the elderly. British Journal of Clinical Psychology, 36, 341-347.

Puig-Antich, J., Goetz, D., Davies, M., Kaplan, T., Davies, S., Ostrow, L., et al. (1989). A controlled family history study of prepubertal major depressive disorder. Archives of General Psychiatry, 46, 406-418.

Reese, E., \& Fivush, R. (1993). Parental styles for talking about the past. Developmental Psychology, 29, 596-606.

Riutort, M., Cuervo, C., Danion, J.-M., Siegfried Peretti, C., \& Salamé, P. (2003). Reduced level of specific autobiographical memories in schizophrenia. Psychiatry Research, 117, 35-45.

Sampson, M. J., Kinderman, P., Watts, S., \& Sembi, S. (2003). Psychopathology and autobiographical memory in stroke and non-stroke hospitalized patients. International Journal of Geriatric Psychiatry, 18, 23-32.

Swales, M. A., Williams, J. M. G., \& Wood, P. (2001). Specificity of autobiographical memory and mood disturbance in adolescents. Cognition and Emotion, 15, 321-331.

Van Vreeswijk, M. F., \& de Wilde, E. J. (2004). Autobiographical memory specificity, psychopathology, depressed mood and the use of the Autobiographical Memory Test: A meta-analysis. Behaviour Research and Therapy, 42, 731-743.

Weissman, M. M., Wolk, S., Wickramaratne, P., Goldstein, R. B., Adams, P., Greenwald, S., et al. (1999). Children with prepubertal onset major depressive disorder and anxiety grown up. Archives of General Psychiatry, 56, 794-801.

Wenzel, A., Werner, M. M., Cochran, C. K., \& Holt, C. S. (2004). A differential pattern of autobiographical memory specificity: the role of depression, anxiety and childhood trauma. Behaviour Research and Therapy, 39, 409-421.

Wechsler, D. (1991). Echelle d'intelligence de Wechsler pour enfants. Troisième édition [Wechsler Intelligence Scale for Children. Third edition]. Paris: ECPA.

Wessel, I., Meeren, M., Peeters, F., Arntz, A., \& Merckelbach, H. (2001). Correlates of autobiographical memory specificity: The role of depression, anxiety and childhood trauma. Behaviour Research and Therapy, 39, 409-421.

Wessel, I., Merckelbach, H., \& Dekkers, T. (2002). Autobiographical memory specificity, intrusive memory, and general memory skills in Dutch-Indonesian survivors of the Word War II era. Journal of Traumatic Stress, 15, 227-234.

Wilcox, H. C., \& Anthony, J. C. (2004). Child and adolescent clinical features as forerunners of adult-onset major depressive disorder: Retrospective evidence from an epidemiological sample. Journal of Affective Disorder, 82, 9-20.

Williams, J. M. G. (1996). Depression and the specificity of autobiographical memory. In D. Rubin (Ed.), Remembering our past: Studies in autobiographical memory (pp. 244-267). Cambridge, England: Cambridge University Press.

Williams, J. M. G., \& Broadbent, K. (1986). Autobiographical memory in suicide attempters. Journal of Abnormal Psychology, 95, 144-149.

Williams, J. M. G., Ellis, N. C., Tyers, C., Healy, H., Rose, G., \& Macleod, A. K. (1996). The specificity of autobiographical memory and imageability of the future. Memory and Cognition, $24,116-125$.

Williams, J. M. G., Teasdale, J. D., Segal, Z. V., \& Soulsby, J. (2000). Mindfulness-based cognitive therapy reduces overgeneral auto- 


\section{AUTOBIOGRAPHICAL MEMORY IN CHILDREN}

biographical memory in formerly depressed patients. Journal of Abnormal Psychology, 109, 150-155.

Winthorpe, C., \& Rabbit, P. A. (1988). Working memory capacity,

IQ, age, and the ability to recount autobiographical events. In M. M. Gruneberg, P. E. Morris, \& R. N. Sykes (Eds.), Practi- cal aspects of memory: Current research and issues: II (pp. 175-179). Chichester, England: Wiley.

Received February 8, 2006

Accepted August 11, 2006 
Copyright of Journal of Clinical Child \& Adolescent Psychology is the property of Lawrence Erlbaum Associates and its content may not be copied or emailed to multiple sites or posted to a listserv without the copyright holder's express written permission. However, users may print, download, or email articles for individual use. 